\title{
Tradução e prática poética no Romantismo brasileiro
}

Maiza Franco

Universidade Federal de Minas Gerais

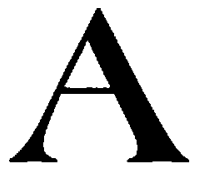

tradução do texto literário, especialmente de textos poéticos, sempre foi um desafio àqueles que se propõem a essa empreitada. A teoria da tradução apresentada pelos poetas concretos teve, sobretudo, o mérito em dar ênfase à idéia da transposição da forma de um texto literário de uma língua para outra. A operação tradutora, tal como eles a propõem, leva em consideração os mecanismos, específicos de cada língua, envolvidos na produção de ęfeito estético. A tradução, portanto, não seria apenas uma transcodificação do significado do texto, mas uma "recriação total" da obra.

$\mathrm{Na}$ tradição brasileira do que eles chamam de "tradução criativa", é citado o nome de Manuel Odorico Mendes, poeta pré-romântico, tradutor de autores gregos e latinos. Haroldo de Campos afirma que teria sido ele o primeiro a propor e praticar uma "verdadeira teoria da tradução", que incluiria a possibilidade de o tradutor enriquecer o léxico da sua língua por meio da criação de palavras. É nesta prática que iremos nos deter, sobretudo, na criação de vocábulos compostos. (cf. CAMPOS, 1970, p.47)

Em nossa língua, a apreensão do pensamento veiculado em textos escritos requer que se percorra um trajeto que se dá, simultaneamente, no tempo e no espaço. Por exemplo, na qualificação de um substantivo é necessário que o leitor primeiro reconheça o objeto a ser qualificado, usualmente nesta ordem, para depois reconhecer a qualificação que lhe é atribuída. Nos casos em que se queira indicar mais de uma qualificação, a relação destas idéias requer extensão temporal ainda maior, o que, na apreensão de uma imagem, poderá ser percebido pelo leitor mais como uma enumeração de atributos do que a constituição de uma imagem completa. No português, a incidência de palavras formadas a partir do processo no qual são unidas duas ou mais palavras, sem mediações 
sintáticas, é bem menor do em outras línguas ocidentais. A respeito desse tema, observou Edward Sapir:

o inglês, aproximando-se nesse passo de uma língua isolante como o chinês, tende à criação de palavras compostas, que se constituem em unidades mais complexas, o que já não acontece com o francês, embora tenha este idioma uma ordem tão rígida para colocar as palavras como o inglês. Para expressar a idéia de 'aguadeiro', diz o chinês 'chui fu' (água homem), e o inglês, para significar 'máquina de escrever' diz 'typewriter' (ou, literalmente 'tipo escritor'). Análogas características apresenta a língua alemã: 'Streichholzschachtel', 'riscomadeiracaixa', isto é, 'caixa de fósforos.' (SAPIR, Edward apud CAMPOS e CAMPOS, 1986, p.127)

A literatura brasileira do século $\mathrm{XX}$, em diálogo com as vanguardas européias, procurou enriquecer a língua através de novas formas de composição. Aqui nos deteremos nas palavras-montagem, ou palavrasvalise, nas quais duas palavras, segmentos de palavras, sufixos, prefixos e/ou desinências são justapostas para formar um novo vocábulo, no qual um conjunto de imagens se torna uma totalidade. A imagem é dada como um todo, não em partes.

No Brasil, entre os nossos modernistas, Oswald de Andrade, em Memórias sentimentais de João Miramar, utiliza esse processo como recurso expressivo: "Beiramarávamos em auto pelo espelho de aluguel arborizado das avenidas marinhas sem sol." (ANDRADE, 1971, p. 42)

Na primeira palavra desse trecho, "beiramarávamos", encontramos reunidas num só vocábulo, flexionado como se fosse um verbo na primeira pessoa do plural do imperfeito do indicativo, as idéais de "beiramar" e "amar" - o que resulta num complexo nocional mais amplo que inclui a paisagem e as ações que nela se praticam. (andar e amar à beira-mar)

A partir dos anos cinqüenta, os poetas Augusto e Haroldo de Campos se viram às voltas com esse procedimento criativo na tradução de fragmentos do Finnegans Wake, de James Joyce, autor que, segundo Haroldo de Campos, utilizou tal processo como ponto de partida e o levou às suas máximas conseqüências, obtendo assim um alto grau de diversificação vocabular. (Cf. CAMPOS e CAMPOS, 1986, p. 22). Antônio Houaiss, como esses poetas, em sua tradução de Ulysses, adotou, em lingua portuguesa, o mesmo processo composicional.

Esses procedimentos, que em determinado momento pareciam a maior das novidades, não eram tão novos assim. Experimentações de 
criação vocabular podem também ser observadas em poetas de séculos anteriores ao século XX. Augusto de Campos, em nossa língua, em sua busca por uma tradição de autores que se valeram desse processo em suas composições, aponta Sousândrade como o "poeta brasileiro que não só se antecipou a Joyce na formaçào de palavras-montagem, como demonstrou, há quase um século, a viabilidade de muitas de suas inovações vocabulares em língua portuguesa." (CAMPOS e CAMPOS, 1986 , p. 124) Nesse retrocesso em busca por um lastro legitimador, encontrou ele ainda Odorico Mendes, "mestre de Sousândrade", e Filinto Elísio, "mestre de Odorico Mendes".

A reivindicação da liberdade de criar novas palavras em língua portuguesa, para atender à necessidade de criação ou de recriação do original, no caso de traduções, não teve em Odorico Mendes um representante isolado; outros escritores, como José Bonifácio, o Velho, já propunham enriquecer a língua portuguesa, principalmente por meio de vocábulos compostos que pudessem constituir imagens poéticas de forma sintética, dando-lhes maior força expressiva.

José Bonifácio, em sua empresa de traduzir os gregos, afirmou ser impossivel traduzir Píndaro com "fidelidade, nobreza e laconismo, mormente nos epítetos compostos, que muitas vezes um só deles forma uma painel completo." (SILVA, 1946, p. 72) Ele nos dá o exemplo de um verso da ode primeira das Olímpicas de Píndaro - uma invocação a Júpiter:

\section{Elatér brontâs akamantópodos.}

(Vibrante agitador do raio de incansáveis pés)

Segundo ele, onde poderiamos achar "uma só palavra que exprima a energia do Elatér, e outra que pinte ao ouvido a rapidez galopante dos dois anapestos do epíteto akamantópodos (incansáveis pés)." (SILVA, 1946, p. 72)

A solução, segundo ele, seria a liberdade de criação, em nossa língua, de vocábulos compostos, que pudessem "pintar" aos ouvidos e aos "olhos da mente" uma cena completa.

Para podermos traduzir dignamente a Píndaro, ser-nos-ia preciso enriquecer primeiro a língua com muitos vocábulos novos, principalmente compostos, como provavelmente fizeram os mesmos Homero e Pindaro para com a sua: se por fatalidade nossa o imortal Camões, que tanto tirou do latim e italiano, nào ignorasse o grego, certo teria dado 
ao seu poema maior força e laconismo, e à língua portuguesa maior ênfase e riqueza. Nós já temos muitos vocábulos compostos tirados do latim, e por que não faremos, e adotaremos muitos outros, tanto ou mais necessários em poesia, como por exemplo: auri-comada, roxicomada, baquimibra, braccirósea, olbinegra, olbi-amorosa, argentipede, tranciloira, docirisonba, docifalante, etc., etc? Ousem pois os futuros engenhos brasileiros, agora que se abre nova época no vasto e nascente Império do Brasil à língua portuguesa, dar este nobre exemplo; e fico, que apesar de franzirem o beiço puristas acanhados, chegará o português, já belo e rico agora, rivalizar em ardimento e concisão com a língua latina, de que traz a origem. (SILVA, 1946, p. 72)

Na Minerva Brasiliense (1843-45), periódico no qual circularam os textos de nossos primeiros românticos, podemos observar que essa prática não se restringiu ao trabalho de tradução, mas se estendeu também à prática poética. O poema de Francisco Gê Acaiaba de Montezuma, "Aos anos de minha mulher a Sra. D. Mariana Angélica de Toledo Marcondes de Montezuma.", nos chamou atenção pelo emprego de palavras compostas. Entre as soluções por ele propostas, podemos citar os seguintes exemplos: a turba "tirse-comada", as orgias "ébri-ludo-festantes" de Vênus; o "áureo-gemante" carro de Apolo; os cisnes "níveo-ad'reçados" do carro de Vênus; a "viti-crinita" chusma de Baco e o champanhe, que ele chama de "niveo-espúmeo" néctar.

Mas a criação de novos vocábulos não foi um fenômeno isolado, restrito ao poema de Montezuma; pelo contrário, foi prática corrente entre os poetas daquela geração. Embora esse poeta, pela freqüência e pelo inusitado das soluções que emprega, seja representativo dessa tendência, podemos encontrar outros casos entre os poetas que publicaram na Minerva Brasiliense. Eis alguns exemplos: Firmino Rodrigues da Silva utilizou o adjetivo "auritingido"; Joaquim Norberto de Sousa Silva criou - verbo "enflechar" e o adjetivo "brônzico"; Antônio Gonçalves Teixeira e Sousa cunhou a palavra "amorabundos"; Manuel Alves Branco fala no "auriverde-crinitas" das laranjeiras; e Pedro José da Costa Barros, em licor "ébri-festivo".

Essa já era, pois, uma das liberdades de expressão reivindicadas pelos nossos primeiros românticos. Domingos José Gonçalves de Magalhães, no prefácio de seu livro Suspiros Poéticos e Saudades, obra inaugural do Romantismo no Brasil, já havia escrito: "Algumas palavras acharão neste Livro que nos dicionários portugueses se não encontram; mas as línguas vivas se enriquecem com o progresso da civilização, e das 
ciências, e uma nova idéia pede um novo termo." (MAGALHÃES, 1986, p. 44-45)

Essas experimentações, no entanto, não foram bem recebidas pela crítica da época, talvez tenha sido este um dos motivos do seu abandono. Sobre a tradução da Iliada, feita por Odorico Mendes, Sílvio Romero fez severas críticas:

A tradução da llíada é cinquenta vezes pior lem comparaçào com a traclução da Odisséial: os crinitos Graios, a clavi-argêntea espada, os bronzeados bucos, as falripas, as adargadas hostes, os hastados socios de topete hirsuto, a olhi-cerúlea-crini-pulcra déia, a predadora Palas pulcricoma, os ungui-sonos cavalos, a crócea aurora, os solípedes, o urbi-frago Pélides, a núncia procelípede, a rija-eri-aguda lança, o velocipede Aquiles, a olhi-táurea Juno, infrugifero ar, os Aqueus amplocomados, e semelhante pragas, que atorcloam por toda a parte.

[...]

As traduções de Odorico Mendes são injustificíveis; este homem, aliás telentoso e ilustrado, foi vítima de um sistema absurdo. Sirva-nos o exemplo e evitemo-lo. (ROMERO, 1953, p. 799-800, v.III.)

Creio, porém, que pelo menos um outro fator contribuiu para o abandono dessa prática em nossa poesia durante algum tempo. Além da crítica negativa com que foi recebida a novidade, em nossa língua o uso generalizado desse processo de criação verbal não foi incorporado à prática cotidiana e espontânea dos falantes da lingua. Em outras palavras, para empregar a expressão de Laudelino Freire, cliríamos que tais procedimentos não participam da "índole" do idioma.

\section{Referências bibliográficas}

ANDRADE, Oswald. Memórias sentimentais de Joào Miramar. Serafim Ponte Grande. 3. ed. Rio de Janeiro: Civilizaçào brasileira, 1971.

CAMPOS, Augusto de e CAMPOS, Haroldo de. Panorama de Finnegans Wake. 3. ed. São Paulo: Perspectiva: 1986.

CAMPOS, Haroldo de. Metalinguagem e outras metas. São Paulo: Perspectiva: Petrópolis: Vozes, 1970.

FREIRE, Laudelino. Regras práticas para bem escrever. Rio de Janeiro: Lótus do Saber, 2000. 
MAGALHÃES, Domingos José Gonçalves de. Suspiros poéticos e saudades. Brasilia: UnB, 1986. [Reprodução fac-similar]

MINERVA BRASILIENSE, Jornal de Ciências, Letras e Artes. Rio de Janeiro, 18431845. [Cópia microfilmada da Biblioteca Nacional do Rio de Janeiro]

ROMERO, Sílvio. História da literatura brastleira. 5. ed. Rio de Janeiro: José Olympio. 1953. 5v.

SILVA, José Bonifácio de Andrada e . Poesias . 4. ed. Rio de Janeiro: INL, 1946.

\section{Resumo}

Comentários sobre a tradução e a prática poética na tradição literária brasileira.

\section{Résumé}

Commentaires sur la traduction et la pratique poétique dans la tradition littéraire bresilienne. 